\title{
ANALISIS PERSEPSI EMPLOYEE EMPOWERMENT TERHADAP EMPLOYEE TURNOVER INTENTION DI HOTEL X, KUPANG, NUSA TENGGARA
}

\author{
Deborah Christine Widjaja, Margarita Fulbertus, Fenny Kusuma D.W. \\ Manajemen Perhotelan, Universitas Kristen Petra, Surabaya, Indonesia \\ e-mail:
}

\begin{abstract}
Abstrak: Penelitian ini dilakukan untuk mengetahui pengaruh persepsi employee empowerment yang sudah dilakukan oleh hotel X kepada karyawan terhadap keinginan karyawan untuk keluar dari hotel X yang merupakan salah satu hotel berbintang 3 di Kupang, Nusa Tenggara Timur yang memiliki masalah turnover karyawan. Hasil analisis membuktikan bahwa persepsi employee empowerment karyawan secara simultan berpengaruh terhadap turnover intention. Namun secara parsial, terbukti bahwa ada 5 variabel dari persepsi employee empowerment yang berpengaruh secara signifikan terhadap turnover intention sedangkan 2 variabel lainnya tidak berpengaruh signifikan. Sedangkan variabel yang paling dominan berpengaruh adalah meaningfulness.
\end{abstract}

Kata kunci: Persepsi, Employee Empowerment, Employee Turnover Intention

\begin{abstract}
This research is going to analyze the influence of employee's perception to the empowerment that has been done by the company towards employee turnover intention. Hotel $X$ is one of the three stars hotels in Kupang, Nusa Tenggara Timur that is having the employee turnover problem. Based on the analysis, employee empowerment perception simultaneously gives influence on the employee turnover intention. However, out of the seven variables of employee empowerment, there are only five variables which significantly influence the turnover intention; while the other two variables do not give a significant influence on the turnover intention. Moreover, meaningfulness is the most dominant variable in giving influence on the employee turnover intention.
\end{abstract}

Keywords: Perception, Employee Empowerment, Employee Turnover Intention

Employee Empowerment merupakah salah satu pendekatan dalam pengelolaan sumber daya manusia yang efektif khususnya dalam industri jasa. Dalam hal ini, industri jasa selalu menekankan pada penyampaian layanan yang dapat diandalkan salah satunya dengan memastikan bahwa karyawan sebagai penyedia jasa dapat memberikan respon yang cepat dan tepat terhadap kebutuhan pelanggan. Employee Empowerment meliputi pembagian otoritas pengambilan keputusan kepada karyawan yang diberdayakan. Karyawan diberikan kemandirian dalam mengambil keputusan tertentu dan menyelesaikan persoalan yang dihadapi pada saat menyampaikan layanan kepada pelanggan tanpa campur tangan dari penyelia atau manajer. Seringkali perusahaan jasa menerapkan employee empowerment khususnya dalam hal penanganan keluhan pelanggan atau pada saat karyawan harus mengupayakan tercapainya kepuasan pelanggan dengan melakukan apapun untuk dapat memenuhi kebutuhan pelanggan dan bahkan memberikan solusi terhadap permasalahan yang dihadapi pelanggan demi tercapainya kepuasan pelanggan. (Lashley, 2001). Sebagai contoh, pada bisnis restoran, server seringkali diberikan empowerment untuk dapat memberikan pelayanan yang terbaik seperti: mengganti makanan dengan yang baru saat pelanggan menyampaikan keluhan berkaitan dengan kualitas makanan yang disajikan dan bahkan terkadang memberikan 'complimentary' berupa minuman gratis untuk menyampaikan permohonan maaf dan mempertahankan kesetiaan pelanggan.

Berdasarkan sebuah penelitian yang pernah dilakukan terkait dengan employee empowerment mengindikasikan bahwa employee empowerment akan meningkatkan perasaan berarti karyawan dalam melakukan pekerjaannya sehingga dapat memfasilitasi meningkatnya komitmen karyawan dan mengurangi keinginan karyawan untuk keluar. (Mishra \& Spreitzer, 1998). Lebih lanjut, Salazar (2000) melalui penelitiannya membuktikan adanya hubungan yang kuat antara employee empowerment dan organizational commitment. Dalam hal ini, karyawan akan semakin meningkat komitmennya terhadap organisasi apabila diberdayakan secara tepat oleh perusahaan. Demikian pula, Light (2004) melalui penelitian yang dilakukannya membuktikan bahwa terdapat hubungan yang kuat dan signifikan antara employee empowerment terhadap employee satisfaction, dan terdapat hubungan yang kuat dan signifikan antara employee satisfaction terhadap keinginan karyawan untuk tetap tinggal dan bekerja untuk perusahaan atau pemberi kerja. 
Mengacu pada hasil penelitian tersebut diatas, penulis melihat kemungkinan adanya hubungan antara penerapan employee empowerment dengan pengendalian turnover karyawan yang seringkali menjadi permasalahan yang dihadapi oleh organisasi terutama pada hospitality industry seperti misalnya hotel. Turnover bisa berdampak negatif dan positif bagi perusahaan. Jika suatu perusahaan kehilangan $20 \%$ orang yang dirasakannya mempunyai performance yang tinggi, maka tentu saja hal itu berdampak negatif karena berdasarkan studi yang ada, karyawan yang mempunyai performance yang tinggi memiliki kontribusi rata-rata 10 kali lebih banyak daripada karyawan umumnya. Oleh sebab itu perusahaan harus menjaga tingkat turnover karyawan dengan high performance dibawah 5\%. Tetapi jika perusahaan kehilangan orang yang dirasakannya mempunyai performance yang rendah sebanyak $20 \%$, maka hal ini berdampak positif bagi perusahaan karena dapat diganti dengan orang yang memiliki performance yang lebih baik (Sullivan, 2009). Hal demikian juga didukung oleh Mello (2002), dengan adanya turnover perusahaan dapat memperkerjakan karyawan-karyawan baru yang membawa ide-ide baru yang mungkin dapat menjadi point penting bagi perusahaan stagnant atau perusahaan yang memerlukan inovasi. Namun jika persentase turnover dalam suatu perusahaan cukup tinggi maka akan mengakibatkan kerugian bagi perusahaan baik itu dalam financial maupun waktu (Handoyo, 1987). Karena dengan adanya turnover berarti perusahaan kehilangan sejumlah tenaga kerja dan kehilangan ini harus diganti dengan karyawan baru. Perusahaan harus mengeluarkan biaya mulai dari perekrutan hingga mendapatkan tenaga kerja siap pakai. Karyawan baru juga membutuhkan waktu untuk proses penyesuaian dan adaptasi. Selain mengalami kerugian dalam hal biaya dan waktu, turnover dapat berpengaruh juga terhadap kelangsungan operasional perusahaan. Selain itu keberhasilan suatu perusahaan untuk mencapai tujuan bersama, tidak lepas dari tingkat konsentrasi yang tinggi untuk semua bagian. Jika manajemen disibukkan dengan keluar masuknya karyawan, hal ini akan mempengaruhi kinerja perusahaan secara keseluruhan. Karena itu, perusahaan harus dapat mengendalikan tingkat turnover karyawan agar dapat menghemat biaya, waktu, dan tetap menjaga kelangsungan operasional perusahaan. Perusahaan harus menjaga tingkat turnover karyawan dengan low performance agar tidak lebih dari 10\% (Sullivan, 2009). Hal yang sama juga didukung oleh Roseman (1981) dalam bukunya Managing Turnover yang menyatakan bahwa jika annual turnover di dalam suatu perusahaan melebihi angka $10 \%$, maka turnover di dalam perusahaan tersebut dapat dikategorikan tinggi.
Berdasarkan data yang diperoleh dari salah satu hotel berbintang 3 di Kupang, Nusa Tenggara Timur, rata-rata tingkat turnover selama tahun 2008 yang paling tertinggi berasal dari divisi Food \& Beverage Service yaitu sebesar $18,1 \%$, kemudian diikuti dengan divisi Front Office sebesar 15,38\% , kemudian diikuti juga dari divisi Accounting sebesar 11,76\%. Dari data yang diperoleh tersebut dapat dilihat bahwa tingkat turnover karyawan di Hotel X, Kupang, Nusa Tenggara Timur, cukup tinggi. Menurut Roseman (1981) jika annual turnover di dalam suatu perusahaan melebihi angka 10\%, maka turnover di dalam perusahaan tersebut dapat dikategorikan tinggi. Namun di lain pihak ternyata hotel $\mathrm{X}$ telah menerapkan employee empowerment.

Terkait dengan fenomena tersebut diatas maka penulis merumuskan permasalahan yang akan diteliti lebih lanjut sebagai berikut:

1. Apakah persepsi employee empowerment secara simultan berpengaruh signifikan terhadap employee turnover intention di hotel X?

2. Apakah persepsi employee empowerment secara parsial berpengaruh signifikan terhadap employee turnover intention di hotel $\mathrm{X}$ ?

3. Diantara beberapa variabel persepsi employee empowerment mana yang paling dominan berpengaruh terhadap employee turnover intention di hotel $X$ ?

\section{BATASAN PENELITIAN}

Menurut Roos (1999) faktor-faktor yang menyebabkan terjadinya turnover karyawan dalam suatu perusahaan sangat luas. Oleh karena itu, dalam penelitian ini, variabel dependen yang diteliti merupakan faktor internal dalam perusahaan yaitu employee empowerment. Employee empowerment yang telah dilakukan akan menjadi stimulus dalam membentuk persepsi employee empowerment. Persepsi employee empowerment meliputi 2 perspektif yaitu psychological empowerment dan organizational empowerment. Psychological empowerment sendiri terdiri dari empat faktor yaitu meaningfulness, competence, self-determination, dan impact. Sedangkan organizational empowerment terdiri dari tiga faktor yaitu dynamic structural framework, control of workplace, dan fluidity in information sharing.

Proses turnover pada dasarnya diawali oleh suatu kondisi yang disebut turnover intention atau keinginan karyawan untuk keluar dari perusahaan. Parasuraman (1989) dalam penelitiannya mengenai turnover menegaskan bahwa turnover intention merupakan faktor yang menentukan actual turnover dari suatu perusahaan. Karena itu penelitian ini meneliti turnover intention sebagai variabel dependen. Penelitian ini menggunakan teori dari Lum serta Hom dan Griffeth 
sebagai penentuan indikator turnover intention Namun point ke-3 dalam teori Hom dan Griffeth yaitu karyawan memiliki keinginan untuk keluar, tidak digunakan karena telah diwakili oleh teori Lum.

\section{TEORI PENUNJANG}

\section{Persepsi}

Menurut Nord dalam Gibson (1985) persepsi adalah "proses pemberian arti (cognitive) terhadap lingkungan oleh seseorang. Karena setiap orang memberi arti kepada stimulus, maka individu yang berbeda akan " melihat" hal yang sama dengan cara yang berbeda-beda" (p.56). Lebih lanjut Thoha (1997) mengemukakan bahwa "persepsi pada hakikatnya adalah proses kognitif yang dialami oleh setiap orang di dalam memahami informasi tentang lingkungannya, baik lewat penglihatan, pendengaran, penghayatan, perasaan, dan penciuman" (pp.141-142). Sedangkan Robbins (1994) mengartikan persepsi sebagai suatu proses dengan mana individu-individu mengorganisasikan dan menafsirkan kesan-kesan panca indera yang diterima agar memberikan arti bagi lingkungannya.

Dalam hal ini terbentuknya persepsi diawali dengan adanya informasi tentang lingkungan yang ditangkap dengan panca indera kemudian dengan melibatkan proses kognitif dan keadaan emosional seseorang akan memberikan tanggap atau tindakan atas objek tersebut. Persepsi adalah proses memberi makna pada sensasi sehingga manusia memperoleh pengetahuan yang baru. Oleh karena itu, persepsi dapat disimpulkan sebagai proses individual yang berupa menerima, menilai informasi yang diterima melalui panca indera dan mengelola berdasarkan pengalaman pribadi.

\section{Employee Empowerment}

Menurut Stewart (1998) employee empowerment berarti memampukan dan memberi kesempatan kepada karyawan untuk merencanakan, melaksanakan rencana, dan mengendalikan rencana pekerjaan yang menjadi tanggung jawabnya atau tanggung jawab kelompoknya. Sedangkan Luthans (1998) mendefinisikan empowerment sebagai wewenang dalam membuat keputusan dalam sebuah area pekerjaan tanpa membutuhkan persetujuan dari orang lain.

Empowerment dapat dibagi menjadi dua perspektif umum yaitu: relational perspective (organizational empowerment) dan psychological perspective (psychological empowerment). Relational empowerment meyakini bahwa empowerment tercipta ketika tingkatan yang lebih tinggi dalam hirarki perusahaan membagi kekuasaannya kepada tingkatan yang lebih rendah. Sedangkan psychological perspective fokus pada persepsi empowerment yang dimiliki karyawan. Psychological empowerment merupakan variabel yang merefleksikan atau mencerminkan tingkatan empowerment yang dirasakan karyawan. (Spreitzer, 1997; Conger dan Kanungo, 1988)

\section{Psychological Empowerment}

Thomas dan Velthouse (1990) membagi physicological empowerment menjadi empat faktor yaitu:

1. Meaningfulness: nilai dari sebuah goal atau tujuan pekerjaan yang dicapai oleh seorang individu sehubungan dengan idealisme atau standar individu tersebut (Thomas dan Velthouse, 1990). Spreitzer (1997) menambahkan bahwa meaningfulness akan tercipta ketika karyawan merasakan bahwa pekerjaannya berarti dan penting baginya. Pekerjaan dirasakan berarti oleh karyawan ketika goal atau tujuan dari aktivitas pekerjaan yang dilakukan sesuai dengan sistem nilai ideal atau standar orang tersebut.

2. Competence: keyakinan yang dimiliki karyawan terhadap kemampuannya (capability) untuk melaksanakan tugas atau pekerjaan sesuai atau berdasarkan skill yang dimilikinya (Thomas dan Velthouse, 1990). Menurut Conger dan Kanungo (1998), tanpa rasa percaya diri terhadap kemampuan diri sendiri, karyawan akan merasa tidak mampu dan kurang diberdayakan.

3. Self-determination: mengacu pada persepsi karyawan terhadap otonomi yang dimilikinya dalam memprakarsai dan mengatur tindakannya dalam pekerjaan. Jika karyawan berkeyakinan bahwa karyawan hanya mengikuti perintah yang diberikan dari orang yang tingkat hirarkinya lebih tinggi dalam suatu perusahaan maka mereka akan merasa tidak diberdayakan (not feel empowered). Self-determination melibatkan tanggung jawab perorangan karyawan terhadap tindakan yang telah diambil.

4. Impact: seberapa besar pengaruh hasil pekerjaan yang dilakukan seorang karyawan di dalam sebuah lingkungan kerja. Karyawan akan merasa diberdayakan ketika individu memiliki keyakinan bahwa pekerjaan atau tindakan yang individu lakukan mempengaruhi dan berdampak pada sistem perusahaan.

\section{Organizational Empowerment}

Matthews et al. (2003) membagi organizational empowerment dalam beberapa faktor:

1. Dynamic Structural Framework: tercipta ketika sebuah perusahaan menyediakan sebuah pedoman 
(guidelines) yang dapat dimodifikasi untuk membantu karyawan. DSF ini memfasilitasi dan sangat membantu karyawan dalam membuat keputusan didalam lingkungan kerja yang sedang berkembang. Quinn dan Spreitzer (1997) menambahkan bahwa di dalam DSF penting bagi karyawan untuk mengerti visi dan goal dari sebuah perusahaan agar program empowerment dapat berjalan secara efektif. Karyawan juga harus merasa memiliki pengaruh dan terlibat didalam pembentukan visi dan misi perusahaan serta memodifikasi pedoman dalam pembuatan keputusan (decision making guidelines). DSF ini memberikan kesempatan kepada sebuah perusahaan untuk mendapatkan input dari karyawan agar perusahaan menjadi lebih fleksibel terhadap perkembangan lingkungan bisnis.

2. Control of Workplace Decisions: tercipta ketika karyawan mendapatkan kesempatan untuk memberikan masukan didalam seluruh aspek karir profesional karyawan. Menurut Wilkinson (1988) agar tercipta persepsi empowerment, individual dan tim harus mempunyai kontrol terhadap bermacam-macam tanggung jawab yang dimiliki misalnya: penjadwalan kerja (scheduling), memperkerjakan pegawai baru, pengembangan karyawan, dan seterusnya.

3. Fluidity in Information Sharing: tercipta ketika informasi yang menyangkut perusahaan dapat diakses oleh semua individu didalam perusahaan. Dalam konteks ini informasi yang dapat diakses adalah informasi yang berkaitan dengan functioning perusahaan. Tidak semua informasi yang berkaitan dengan karyawan dapat diberikan, misalnya personnel records atau laporan evaluasi karyawan oleh manager. Karyawan harus merasa bahwa perusahaan mempunyai metode komunikasi yang multidirectional dan efisien untuk berbagi informasi-informasi penting diantara semua level di perusahaan. Wilkinson (1998) menyatakan bahwa karyawan tidak hanya dibatasi dengan kemampuan untuk saling berbagi informasi yang berkaitan dengan pekerjaan, tetapi juga harus mampu untuk mengekspresikan ide-ide dan keluhan-keluhan para karyawan.

\section{Turnover Intention}

Turnover intention pada dasarnya adalah keinginan karyawan untuk dari satu tempat kerja ke tempat kerja lainnya. Hal tersebut menunjukkan bahwa turnover intention adalah keinginan untuk berpindah, belum sampai pada tahap realisasi yaitu melakukan perpindahan dari satu tempat ke tempat kerja lainya. (Harnoto, 2002)
Intensi keluar merupakan ketidakpuasan terhadap pekerjaan yang dapat memicu keinginan seseorang untuk keluar mencari pekerjaan yang baru. Tingkat keluar masuknya tenaga kerja yang tinggi selain dapat mengganggu kelangsungan kerja juga dapat mengganggu kelangsungan proses produksi, bila tingkat intensi keluar karyawan mencapai $2 \%$ keatas bisa dikategorikan tinggi, maka memerlukan penanganan yang serius dari perusahaan, sebab bila dibiarkan terus berlangsung, berakibat bukan hanya produksi saja terlebih lagi terhadap mental karyawan yang masih bertahan pada perusahaan. (Harnoto, 2002)

\section{Komponen-Komponen Turnover Intention}

Menurut Lum et. al. (1998) menyatakan bahwa intensi keluar merupakan variabel yang paling berhubungan dan lebih banyak menjelaskan perilaku turnover. Dimana keinginan untuk keluar dapat diukur dengan 3 komponen berikut ini:

1. Keinginan untuk mencari pekerjaan baru di bidang yang sama di perusahaan lain.

Melihat adanya perusahaan lain yang dirasa mampu memberikan keuntungan lebih banyak dibandingkan tempat dia bekerja saat ini, dapat menjadi alasan utama bagi individu untuk memicu keinginannya keluar dari perusahaan. Namun hal itu akan terbatas di saat dia hanya akan menerima jika sesuai dengan keahliannya saat ini.

2. Keinginan untuk mencari pekerjaan baru di bidang yang berbeda di perusahaan lain.

Seorang individu yang merasa selama ini kurang mengalami kemajuan pada pekerjaan akan mencoba untuk beralih pada bidang yang berbeda. Tanpa harus mempelajari keahlian baru, individu tersebut mencari pekerjaan di bidang yang baru dengan keahlian sama dengan yang dia miliki saat ini.

3. Keinginan untuk mencari profesi baru.

Dengan memiliki keahlian yang cukup banyak, maka akan mudah bagi seseorang untuk timbul keinginan mencari pekerjaan baru yang sebelumnya tidak pernah dia kerjakan.

Hom dan Griffeth (1991) mengemukakan bahwa intensi keluar karyawan dapat diukur dengan mengembangkan pertanyaan sebagai berikut (dalam Panggabean, 2004, p.141):

1. Adanya pemikiran untuk meninggalkan pekerjaan.

2. Karyawan telah mengevaluasi kerugian yang diakibatkan jika keluar dari pekerjaan.

3. Karyawan memiliki keinginan untuk keluar.

Karyawan memiliki kemungkinan untuk pindah pekerjaan pada waktu yang akan datang. 


\section{Kerangka Pemikiran}

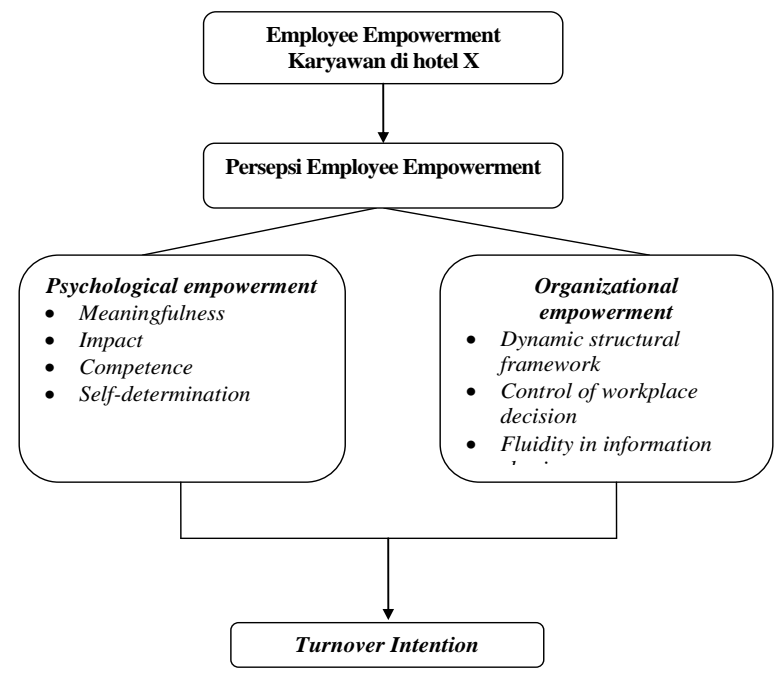

Sumber: Diadopsi dari Kazlauskaite, Buciuniene, Turauskas (2006); Sanderson (2003); dan Nedd (2006)

\section{Gambar 1. Kerangka Pemikiran}

\section{Hipotesis}

Mengacu pada hasil penelitian yang sebelumnya maka dapat disusun hipotesis sebagai berikut:

1. Diduga variabel-variabel persepsi employee empowerment secara simultan berpengaruh signifikan terhadap employee turnover intention di hotel $\mathrm{X}$.

2. Diduga variabel-variabel persepsi employee empowerment secara parsial berpengaruh signifikan terhadap employee turnover intention di hotel X.

3. Diduga variabel meaningfulness merupakan faktor yang paling dominan berpengaruh terhadap employee turnover intention di hotel X.

\section{METODE PENELITIAN}

\section{Jenis Penelitian}

Jenis penelitian ini adalah penelitian kuantitatif yang merupakan penelitian deskriptif kausal. Penelitian ini menggunakan hipotesis yang ditujukan untuk mengetahui pengaruh persepsi employee empowerment terhadap employee turnover intention di hotel X, Kupang, Nusa Tenggara Timur. Penelitian empiris dilakukan setelah hipotesis dirumuskan, dimana nantinya data dari penelitian empiris dibandingkan dengan hipotesis yang akan menentukan penulis untuk menolak atau menerima hipotesis.

\section{Gambaran Populasi dan Sampel}

Dalam penelitian ini, yang menjadi populasi adalah seluruh karyawan tetap yang bekerja di hotel $\mathrm{X}$ yang berjumlah 145 orang pada periode April 2009.
Sedangkan sampel yang diambil dalam penelitian ini adalah karyawan tetap yang bekerja di hotel $\mathrm{X}$ dengan teknik pengambilan secara proporsional dari masingmasing departemen.

Teknik pengambilan sampel adalah nonprobability sampling dimana pada rancangan sampel non-probabilitas penarikan sampel tidak penuh dilakukan dengan menggunakan hukum probabilitas, artinya bahwa tidak semua unit populasi memiliki kesempatan untuk dijadikan sampel penelitian. Selain itu, juga ditentukan berdasarkan quota sampling, yaitu peneliti mengklasifikasikan populasi menurut kriteria tertentu, dalam penelitian ini populasi diklasifikasikan menurut departemen, kemudian proporsi sampel yang dikehendaki untuk tiap kelas ditentukan, setelah itu barulah ditentukan kuota untuk setiap klasifikasi.

Jumlah minimal sampel dalam penelitian ini dihitung berdasarkan rumus Sugiyono (2008)

$$
n=\frac{(\lambda)^{2} \cdot N \cdot P \cdot Q}{d^{2}(N-1)+\lambda^{2} \cdot P \cdot Q}
$$

$\lambda^{2}=1,96=$ harga kurva normal pada alpha 0,05

$P=Q=0,5$

$d=0,05$

$n=$ Jumlah sampel

$N=$ Jumlah populasi

Berdasarkan perhitungan rumus diatas dengan jumlah populasi 145 orang karyawan tetap, maka diperoleh minimal sampel yang diteliti adalah 105,4 yang dibulatkan menjadi 105 orang karyawan tetap. Jumlah minimal sampel ini kemudian diambil secara proporsional dari tiap-tiap departemen.

\section{Tabel 1. Tabel Proporsi Jumlah Sampel}

\begin{tabular}{lccr}
\hline Departemen & $\begin{array}{c}\text { Jumlah } \\
\text { Karyawan } \\
\text { Tetap }\end{array}$ & $\begin{array}{c}\text { Persentase } \\
\text { Proporsi (\%) }\end{array}$ & $\begin{array}{c}\text { Jumlah } \\
\text { Sampel }\end{array}$ \\
\hline Front Office & 13 & 8,57 & 9 \\
Housekeeping & 46 & 31,42 & 33 \\
F \& B & 34 & 25,71 & 27 \\
Accounting & 17 & 11,42 & 12 \\
Marketing & 6 & 3,80 & 4 \\
EDP & 2 & 1 & 1 \\
HR & 10 & 6,66 & 7 \\
Security & 8 & 5,71 & 6 \\
Engineering & 9 & 5,71 & 6 \\
\hline Total & 145 & 100 & 105 \\
\hline
\end{tabular}

\section{Jenis dan Sumber Data}

Dalam penelitian ini jenis data yang dikumpulkan untuk diolah dan dianalisa yaitu:

1. Data primer adalah data yang dikumpulkan langsung melalui obyeknya (sumber utama) yaitu karyawan tetap di tiap departemen yang bekerja di hotel $\mathrm{X}$, melalui daftar pertanyaan atau kuisioner. 
2. Data sekunder adalah data yang diperoleh dari:

a. Internal data turnover dan jumlah karyawan hotel X

b. Wawancara dengan pihak hotel $\mathrm{X}$ untuk mengetahui employee empowerment yang telah dilakukan.

\section{Identifikasi Variabel dan Definisi Operasional Variabel}

Dalam penelitian ini variabel yang digunakan adalah variabel bebas (independen variabel) dan variabel terikat (dependen variabel). Variabel bebas dengan notasi $\mathrm{X}$ dan variabel terikat dengan notasi $\mathrm{Y}$.

Variabel bebas $(\mathrm{X})$ :

$\mathrm{X}_{1}=$ Meaningfulness (psychological empowerment)

$\mathrm{X}_{2}=$ Competence (psychological empowerment)

$\mathrm{X}_{3}=$ Self-determination (psychological empowerment)

$\mathrm{X}_{4}=$ Impact (psychological empowerment)

$\mathrm{X}_{5}=$ Dynamic structural framework (organizational empowerment)

$\mathrm{X}_{6}=$ Control of workplace decisions (organizational empowerment)

$\mathrm{X}_{7}=$ Fluidity in information sharing (organizational empowerment)

Variabel terikat $(\mathrm{Y})$ :

$\mathrm{Y}=$ Employee turnover intention

\section{Variabel Meaningfulness $\left(\mathrm{X}_{1}\right)$}

Meaningfulness berarti pekerjaan yang dilakukan karyawan tersebut dirasakan bernilai atau bermakna oleh karyawan berdasarkan ideal atau standar yang dimiliki masing-masing karyawan tersebut. Meaningfulness pada penelitian ini menggunakan indikator:

1. Pekerjaan karyawan yang dilakukan merupakan hal yang penting bagi dirinya.

2. Aktifitas kerja yang dilakukan karyawan secara pribadi berarti bagi dirinya.

3. Pekerjaan yang karyawan lakukan sesuai dengan idealisme karyawan.

\section{Variabel Competence $\left(\mathrm{X}_{2}\right)$}

Competence berarti karyawan tersebut yakin akan kemampuan yang dimilikinya untuk melaksanakan tugas atau pekerjaan sesuai dengan skill yang dimilikinya. Competence pada penelitian ini menggunakan indikator:

1. Karyawan mampu menyelesaikan tugas dengan jangka waktu yang telah ditentukan.

2. Karyawan menguasai keterampilan yang diperlukan untuk melakukan pekerjaannya.
3. Karyawan memiliki kepercayaan diri terhadap kemampuan yang dimilikinya untuk menyelesaikan pekerjaan.

\section{$\underline{\text { Variabel Self-determination }}\left(\mathrm{X}_{3}\right)$}

Self-determination berarti karyawan memiliki otonomi dalam memprakarsai dan mengatur tindakannya dalam pekerjaan. Self-determination pada penelitian ini menggunakan indikator:

1. Karyawan memiliki keleluasaan dalam menentukan bagaimana ia menyelesaikan pekerjaannya.

2. Karyawan mempunyai kesempatan untuk menggunakan inisiatif dalam melaksanakan pekerjaan.

3. Karyawan mempunyai peluang untuk tidak bergantung kepada atasan dalam melaksanakan pekerjaannya.

Variabel Impact $\left(\mathrm{X}_{4}\right)$

Impact berarti seberapa besar pengaruh hasil pekerjaan yang dilakukan seorang karyawan di dalam sebuah lingkungan kerja. Impact pada penelitian ini menggunakan indikator:

1. Karyawan mempunyai pengaruh yang besar terhadap keberhasilan pekerjaan di departemennya.

2. Hasil kerja karyawan berdampak pada sistem perusahaan.

3. Opini yang diberikan karyawan menjadi bahan pertimbangan dalam pengambilan keputusan departemen.

\section{Variabel Dynamic structural framework $\left(\mathrm{X}_{5}\right)$}

Dynamic structural framework berarti sebuah perusahaan menyediakan sebuah pedoman (guidelines) yang dapat dimodifikasi untuk karyawan. Dynamic structural framework pada penelitian ini menggunakan indikator:

1. Perusahaan menyediakan informasi mengenai apa yang ingin dikerjakan oleh perusahaan di masa yang akan datang.

2. Perusahaan menyediakan informasi tentang bagaimana cara untuk meraih goal atau tujuan perusahaan.

3. Perusahaan menyediakan pedoman untuk menyelesaikan tugas karyawan dengan baik.

4. Karyawan dapat memodifikasi pedoman dalam mengambil keputusan.

5. Karyawan dilibatkan dalam pembentukan visi perusahaan.

6. Karyawan dilibatkan dalam pembentukan misi perusahaan.

Variabel Control of workplace decisions (X6)

Control of workplace decisions berarti karyawan mendapatkan kesempatan untuk memberikan masukan 
didalam semua aspek karir professional mereka. Control of workplace decisions pada penelitian ini menggunakan indikator:

1. Karyawan dapat memberikan masukan pembentukan program untuk pengembangan skill karyawan.

2. Karyawan dapat memberikan masukan dalam hal mempekerjakan karyawan baru.

3. Karyawan mempunyai keleluasaan dalam mengambil cuti mereka.

4. Karyawan dapat memberikan pendapat dalam mengubah kebijakan perusahaan.

\section{Variabel Fluidity in information sharing $\left(\mathrm{X}_{7}\right)$}

Fluidity in information sharing berarti informasi yang menyangkut perusahaan dapat diakses oleh semua individu didalam perusahaan. Fluidity in information sharing pada penelitian ini menggunakan indikator:

1. Perusahaan memiliki cara yang efisien untuk menyebarkan informasi kepada seluruh tingkat hirarki perusahaan.

2. Perusahaan memliki cara yang efektif untuk menyebarkan informasi kepada seluruh tingkat hirarki perusahaan.

3. Perusahaan menyediakan informasi kepada karyawan mengenai customer.

4. Perusahaan menyediakan akses kepada sumber informasi yang dibutuhkan karyawan dalam menyelesaikan pekerjaan.

\section{Variabel Employee Turnover Intention (Y)}

Employee Turnover Intention adalah keinginan karyawan untuk keluar dari perusahaan. Employee turnover intention pada penelitian ini diukur dengan pertanyaan yang dikembangkan dari Lum et.al (1998, pp.305-320), Hom dan Griffeth (1991) dalam Panggabean (2004) yang meliputi:

1. Keinginan mencari pekerjaan di bidang yang sama di perusahaan lainnya.

2. Keinginan mencari pekerjaan baru di bidang yang berbeda.

3. Keinginan untuk mencari profesi baru.

4. Adanya pemikiran untuk meninggalkan pekerjaan.

5. Karyawan telah mengevaluasi kerugian yang diakibatkan jika keluar dari pekerjaan.

6. Karyawan memiliki kemungkinan untuk pindah pekerjaan pada waktu yang akan datang.

\section{TEKNIK ANALISIS DATA}

\section{Statistik Deskriptif}

Dalam penelitian ini penulis melakukan penghitungan distribusi frekuensi dan mean yang menggambarkan data yang diperoleh dari tabulasi jawaban responden.

\section{Analisis Regresi Linier Berganda}

Analisis yang digunakan pada penelitian ini adalah regresi linier berganda. Rumus regresi berganda untuk mengetahui pengaruh persepsi employee empowerment terhadap employee turnover intention adalah sebagai berikut :

$Y=\alpha+\beta_{1} X_{1}+\beta_{2} X_{2}+\beta_{3} X_{3}+\beta_{4} X_{4}+\beta_{5} X_{5}+\beta_{6} X_{6}+\beta_{7} X_{7}$ Keterangan :

$\mathrm{Y}=$ Employee Turnover Intention

$\alpha=$ Konstanta regresi

$\beta_{1}=$ Koefisien regresi variabel bebas meaningfulness

$X_{1}=$ Meaningfulness

$\beta_{2}=$ Koefisien regresi variabel bebas competence

$X_{2}=$ Competence

$\beta_{3}=$ Koefisien regresi variabel bebas selfdetermination

$X_{3}=$ Self-determination

$\beta_{4}=$ Koefisien regresi variabel bebas impact

$X_{4}=$ Impact

$\beta_{5}=$ Koefisien regresi variabel bebas dynamic structural framework

$X_{5}=$ Dynamic structural framework

$\beta_{6}=$ Koefisien regresi variabel bebas control of workplace decisions

$X_{6}=$ Control of workplace decisions

$\beta_{7}=$ Koefisien regresi variabel bebas fluidity of information sharing

$X_{7}=$ Fluidity of information sharing

\section{ANALISIS DAN PEMBAHASAN}

\section{Analisis Demografis Responden}

Hasil analisis data demografis responden yang diperoleh penulis yaitu: sebanyak 74 responden berjenis kelamin pria $(70,5 \%)$ dan 31 orang berjenis kelamin perempuan (29,5\%). Sebagian besar responden berusia berkisar antara 31-40 tahun yaitu sebanyak 39\%, kemudian umur 21-30 tahun sebanyak $37,1 \%$. Dari keseluruhan responden terdapat 86 karyawan operasional (81.9\%), 13 orang supervisor $(12,4 \%)$ dan 6 orang department head $(5,7 \%)$. Sedangkan distribusi lama responden telah bekerja di Hotel X sebagian besar selama 1-3 tahun yaitu sebanyak $35,2 \%$. Kemudian karyawan yang bekerja di bawah 1 tahun sebanyak 27,6\%. Karyawan yang bekerja selama 4-6 tahun sebanyak 21,9\% dan yang terakhir adalah karyawan yang bekerja diatas 6 tahun sebanyak $15,2 \%$. 


\section{Analisis Statistik Deskriptif}

Deskripsi Variabel Meaningfulness yang merupakan bagian dari psychological empowerment

Tabel 2. Jawaban Responden Mengenai Meaningfulness

\begin{tabular}{|c|c|c|c|c|c|c|c|c|c|c|c|c|}
\hline \multirow{3}{*}{ Indikator } & \multicolumn{10}{|c|}{ Skor Jawaban } & \multirow{3}{*}{ Mean } & \multirow{3}{*}{ Kategori } \\
\hline & \multicolumn{2}{|c|}{$\begin{array}{c}\text { Sangat } \\
\text { Tidak } \\
\text { Setuju (1) }\end{array}$} & \multicolumn{2}{|c|}{$\begin{array}{c}\text { Tidak } \\
\text { Setuju (2) }\end{array}$} & \multicolumn{2}{|c|}{ Netral (3) } & \multicolumn{2}{|c|}{ Setuju (4) } & \multicolumn{2}{|c|}{$\begin{array}{c}\text { Sangat } \\
\text { Setuju (5) }\end{array}$} & & \\
\hline & Jmlh & $\%$ & Jmlh & $\%$ & Jmlh & $\%$ & Jmlh & $\%$ & Jmlh & $\%$ & & \\
\hline $\begin{array}{l}\text { Pekerjaan yang saya lakukan } \\
\text { merupakan hal yang penting bagi saya }\end{array}$ & 0 & 0 & 4 & 3,8 & 9 & 8,6 & 40 & 38,1 & 52 & 49,5 & 4,33 & $\begin{array}{l}\text { Sangat } \\
\text { Tinggi }\end{array}$ \\
\hline $\begin{array}{l}\text { Aktivitas kerja yang dilakukan oleh } \\
\text { saya secara pribadi berarti bagi saya }\end{array}$ & 0 & 0 & 3 & 2,9 & 15 & 14,3 & 42 & 40 & 45 & 42,9 & 4,23 & $\begin{array}{l}\text { Sangat } \\
\text { Tinggi }\end{array}$ \\
\hline $\begin{array}{l}\text { Pekerjaan yang saya lakukan sesuai } \\
\text { dengan idealisme saya }\end{array}$ & 1 & 1 & 8 & 7,6 & 27 & 25,7 & 51 & 48,6 & 18 & 17,1 & 3,73 & Tinggi \\
\hline Mean Meaningfulness & & & & & & 0984 & & & & & & Tinggi \\
\hline
\end{tabular}

Deskripsi Variabel Competence yang merupakan bagian dari psychological empowerment

Tabel 3. Jawaban Responden Mengenai Competence

\begin{tabular}{|c|c|c|c|c|c|c|c|c|c|c|c|c|}
\hline \multirow{3}{*}{ Indikator } & \multicolumn{10}{|c|}{ Skor Jawaban } & \multirow{3}{*}{ Mean } & \multirow{3}{*}{ Kategori } \\
\hline & \multicolumn{2}{|c|}{$\begin{array}{c}\text { Sangat } \\
\text { Tidak } \\
\text { Setuju (1) }\end{array}$} & \multicolumn{2}{|c|}{$\begin{array}{c}\text { Tidak } \\
\text { Setuju (2) }\end{array}$} & \multicolumn{2}{|c|}{ Netral (3) } & \multicolumn{2}{|c|}{ Setuju (4) } & \multicolumn{2}{|c|}{$\begin{array}{c}\text { Sangat } \\
\text { Setuju (5) }\end{array}$} & & \\
\hline & Jmlh & $\%$ & Jmlh & $\%$ & Jmlh & $\%$ & Jmlh & $\%$ & Jmlh & $\%$ & & \\
\hline $\begin{array}{l}\text { Saya mampu menyelesaikan tugas } \\
\text { dengan jangka waktu yang telah } \\
\text { ditentukan }\end{array}$ & 0 & 0 & 5 & 4,8 & 19 & 18,1 & 52 & 49,5 & 29 & 27,6 & 4,00 & Tinggi \\
\hline $\begin{array}{l}\text { Saya menguasai keterampilan yang } \\
\text { diperlukan untuk melakukan } \\
\text { pekerjaan saya }\end{array}$ & 0 & 0 & 10 & 9,5 & 12 & 11,4 & 63 & 60 & 20 & 19 & 3,89 & Tinggi \\
\hline $\begin{array}{l}\text { Saya memiliki kepercayaan diri } \\
\text { terhadap kemampuan yang saya miliki } \\
\text { untuk menyelesaikan pekerjaan }\end{array}$ & 1 & 1 & 8 & 7,6 & 14 & 13,3 & 51 & 48,6 & 31 & 29,5 & 3,98 & Tinggi \\
\hline Mean Competence & & & & & & 9556 & & & & & & Tinggi \\
\hline
\end{tabular}

Deskripsi Varibel Self-determination yang merupakan bagian dari psychological empowerment

Tabel 4. Jawaban Responden Mengenai Self-determination

\begin{tabular}{|c|c|c|c|c|c|c|c|c|c|c|c|c|}
\hline \multirow{3}{*}{ Pertanyaan } & \multicolumn{10}{|c|}{ Skor Jawaban } & \multirow{3}{*}{ Mean } & \multirow{3}{*}{ Kategori } \\
\hline & \multicolumn{2}{|c|}{$\begin{array}{c}\text { Sangat } \\
\text { Tidak } \\
\text { Setuju (1) } \\
\end{array}$} & \multicolumn{2}{|c|}{$\begin{array}{c}\text { Tidak } \\
\text { Setuju (2) }\end{array}$} & \multicolumn{2}{|c|}{ Netral (3) } & \multicolumn{2}{|c|}{ Setuju (4) } & \multicolumn{2}{|c|}{$\begin{array}{c}\text { Sangat } \\
\text { Setuju (5) }\end{array}$} & & \\
\hline & Jmlh & $\%$ & Jmlh & $\%$ & Jmlh & $\%$ & Jmlh & $\%$ & Jmlh & $\%$ & & \\
\hline $\begin{array}{l}\text { Saya memiliki keleluasaan dalam } \\
\text { menentukan bagaimana saya } \\
\text { menyelesaikan pekerjaan }\end{array}$ & 3 & 2,9 & 17 & 16,2 & 26 & 24,8 & 41 & 39 & 18 & 17,1 & 3,51 & Tinggi \\
\hline $\begin{array}{l}\text { Saya mempunyai kesempatan untuk } \\
\text { menggunakan inisiatif dalam } \\
\text { melaksanakan pekerjaan }\end{array}$ & 3 & 2,9 & 11 & 10,5 & 24 & 22,9 & 45 & 42,9 & 22 & 21 & 3,69 & Tinggi \\
\hline $\begin{array}{l}\text { Saya mempunyai peluang untuk tidak } \\
\text { bergantung pada atasan dalam } \\
\text { melaksanakan pekerjaan }\end{array}$ & 2 & 1,9 & 39 & 37,1 & 25 & 23,8 & 29 & 27,6 & 10 & 9,5 & 3,06 & Sedang \\
\hline Mean Self-determation & & & & & & 4190 & & & & & & Tinggi \\
\hline
\end{tabular}


Deskripsi Variabel Impact yang merupakan bagian dari psychological empowerment

Tabel 5. Jawaban Responden Mengenai Impact

\begin{tabular}{|c|c|c|c|c|c|c|c|c|c|c|c|c|}
\hline \multirow{3}{*}{ Pertanyaan } & \multicolumn{10}{|c|}{ Skor Jawaban } & \multirow{3}{*}{ Mean } & \multirow{3}{*}{ Kategori } \\
\hline & \multicolumn{2}{|c|}{$\begin{array}{c}\text { Sangat } \\
\text { Tidak } \\
\text { Setuju (1) } \\
\end{array}$} & \multicolumn{2}{|c|}{$\begin{array}{c}\text { Tidak } \\
\text { Setuju (2) }\end{array}$} & \multicolumn{2}{|c|}{ Netral (3) } & \multicolumn{2}{|c|}{ Setuju (4) } & \multicolumn{2}{|c|}{$\begin{array}{c}\text { Sangat } \\
\text { Setuju (5) }\end{array}$} & & \\
\hline & Jmlh & $\%$ & Jmlh & $\%$ & Jmlh & $\%$ & Jmlh & $\%$ & Jmlh & $\%$ & & \\
\hline $\begin{array}{l}\text { Saya mempunyai pengaruh yang besar } \\
\text { terhadap keberhasilan pekerjaan di } \\
\text { departemen saya }\end{array}$ & 1 & 1 & 9 & 8,6 & 41 & 39 & 42 & 40 & 12 & 11,4 & 3,52 & Tinggi \\
\hline $\begin{array}{l}\text { Hasil kerja saya berdampak pada } \\
\text { sistem perusahaan }\end{array}$ & 1 & 1 & 13 & 12,4 & 20 & 19 & 56 & 53,3 & 15 & 14,3 & 3,68 & Tinggi \\
\hline $\begin{array}{l}\text { Opini yang saya berikan menjadi } \\
\text { bahan pertimbangan dalam } \\
\text { mengambil keputusan departemen }\end{array}$ & 2 & 1,9 & 33 & 31,4 & 36 & 34,3 & 29 & 27,6 & 5 & 4,8 & 3,02 & Sedang \\
\hline Mean Impact & & & & & & ,4063 & & & & & & Tinggi \\
\hline
\end{tabular}

Deskripsi Variabel Dynamic Structural Framework yang merupakan bagian dari organizational empowerment

Tabel 6. Jawaban Responden Mengenai Dynamic Structural Framework

\begin{tabular}{|c|c|c|c|c|c|c|c|c|c|c|c|c|}
\hline \multirow{3}{*}{ Pertanyaan } & \multicolumn{10}{|c|}{ Skor Jawaban } & \multirow{3}{*}{ Mean } & \multirow{3}{*}{ Kategori } \\
\hline & \multicolumn{2}{|c|}{$\begin{array}{l}\text { Sangat } \\
\text { Tidak } \\
\text { Setuju (1) }\end{array}$} & \multicolumn{2}{|c|}{$\begin{array}{c}\text { Tidak } \\
\text { Setuju (2) }\end{array}$} & \multicolumn{2}{|c|}{ Netral (3) } & \multicolumn{2}{|c|}{ Setuju (4) } & \multicolumn{2}{|c|}{$\begin{array}{c}\text { Sangat } \\
\text { Setuju (5) }\end{array}$} & & \\
\hline & Jmlh & $\%$ & Jmlh & $\%$ & Jmlh & $\%$ & Jmlh & $\%$ & Jmlh & $\%$ & & \\
\hline $\begin{array}{l}\text { Perusahaan menyediakan informasi } \\
\text { mengenai apa yg ingin dikerjakan oleh } \\
\text { perusahaan di masa yang akan datang }\end{array}$ & 1 & 1 & 12 & 11,4 & 25 & 23,8 & 49 & 46,7 & 18 & 17,1 & 3,68 & Tinggi \\
\hline $\begin{array}{l}\text { Perusahaan menyediakan informasi } \\
\text { tentang bagaimana cara untuk meraih } \\
\text { goal atau tujuan perusahaan }\end{array}$ & 1 & 1 & 7 & 6,7 & 18 & 17,1 & 61 & 58,1 & 18 & 17,1 & 3,84 & Tinggi \\
\hline $\begin{array}{l}\text { Perusahaan menyediakan pedoman } \\
\text { untuk menyelesaikan tugas karyawan } \\
\text { dengan baik }\end{array}$ & 0 & 0 & 8 & 7,6 & 24 & 22,9 & 56 & 53,3 & 17 & 16,2 & 3,78 & Tinggi \\
\hline $\begin{array}{l}\text { Saya dapat memodifikasi pedoman } \\
\text { dalam mengambil keputusan yang } \\
\text { disediakan oleh perusahaan }\end{array}$ & 2 & 1,9 & 34 & 32,4 & 27 & 25,7 & 35 & 33,3 & 7 & 6,7 & 3,10 & Sedang \\
\hline $\begin{array}{l}\text { Saya dilibatkan dalam pembentukan } \\
\text { visi perusahaan }\end{array}$ & 6 & 5,7 & 60 & 57,1 & 18 & 17,1 & 17 & 16,2 & 4 & 3,8 & 2,55 & Rendah \\
\hline $\begin{array}{l}\text { Saya dilibatkan dalam pembentukan } \\
\text { misi perusahaan }\end{array}$ & 9 & 8,6 & 61 & 58,1 & 14 & 13,3 & 18 & 17,1 & 3 & 2,9 & 2,48 & Rendah \\
\hline Mean DSF & 3.2381 & & & & & & & & & & & Sedang \\
\hline
\end{tabular}

Deskripsi Variabel Control of Workplace Decisions yang merupakan bagian dari organizational empowerment

Tabel 7. Jawaban Responden Mengenai Control of Workplace Decisions

\begin{tabular}{|c|c|c|c|c|c|c|c|c|c|c|c|c|}
\hline \multirow{3}{*}{ Pertanyaan } & \multicolumn{10}{|c|}{ Skor Jawaban } & \multirow{3}{*}{ Mean } & \multirow{3}{*}{ Kategori } \\
\hline & \multicolumn{2}{|c|}{$\begin{array}{c}\text { Sangat } \\
\text { Tidak } \\
\text { Setuju (1) }\end{array}$} & \multicolumn{2}{|c|}{$\begin{array}{c}\text { Tidak } \\
\text { Setuju (2) }\end{array}$} & \multicolumn{2}{|c|}{ Netral (3) } & \multicolumn{2}{|c|}{ Setuju (4) } & \multicolumn{2}{|c|}{$\begin{array}{c}\text { Sangat } \\
\text { Setuju (5) }\end{array}$} & & \\
\hline & Jmlh & $\%$ & Jmlh & $\%$ & Jmlh & $\%$ & Jmlh & $\%$ & Jmlh & $\%$ & & \\
\hline $\begin{array}{l}\text { Saya dapat memberikan masukan dlm } \\
\text { hal mempekerjakan karyawan baru }\end{array}$ & 2 & 1,9 & 38 & 36,2 & 19 & 18,1 & 36 & 34,3 & 10 & 9,5 & 3,13 & Sedang \\
\hline $\begin{array}{l}\text { Saya dapat memberikan masukan } \\
\text { pembentukan program untuk } \\
\text { pengembangan skill karyawan. }\end{array}$ & 1 & 1 & 33 & 31,4 & 30 & 28,6 & 34 & 32,4 & 7 & 6,7 & 3,12 & Sedang \\
\hline $\begin{array}{l}\text { Saya mempunyai keleluasaan dalam } \\
\text { mengambil cuti saya. }\end{array}$ & 10 & 9,5 & 42 & 40 & 21 & 20 & 27 & 25,7 & 5 & 4,8 & 2,76 & Sedang \\
\hline $\begin{array}{l}\text { Saya dapat memberikan pendapat dlm } \\
\text { mengubah kebijakan perusahaan. }\end{array}$ & 6 & 5,7 & 62 & 59 & 24 & 22,9 & 12 & 11,4 & 1 & 1 & 2,43 & Rendah \\
\hline Mean CWD & & & & & & 8619 & & & & & & Sedang \\
\hline
\end{tabular}


Deskripsi Variabel Fluidity in Information Sharing yang merupakan bagian dari organizational empowerment

Tabel 8. Jawaban Responden Mengenai Fluidity in Information Sharing

\begin{tabular}{|c|c|c|c|c|c|c|c|c|c|c|c|c|}
\hline \multirow{3}{*}{ Pertanyaan } & \multicolumn{10}{|c|}{ Skor Jawaban } & \multirow{3}{*}{ Mean } & \multirow{3}{*}{ Kategori } \\
\hline & \multicolumn{2}{|c|}{$\begin{array}{c}\text { Sangat } \\
\text { Tidak } \\
\text { Setuju (1) }\end{array}$} & \multicolumn{2}{|c|}{$\begin{array}{c}\text { Tidak } \\
\text { Setuju (2) }\end{array}$} & \multicolumn{2}{|c|}{ Netral (3) } & \multicolumn{2}{|c|}{ Setuju (4) } & \multicolumn{2}{|c|}{$\begin{array}{c}\text { Sangat } \\
\text { Setuju (5) }\end{array}$} & & \\
\hline & Jmlh & $\%$ & Jmlh & $\%$ & Jmlh & $\%$ & Jmlh & $\%$ & Jmlh & $\%$ & & \\
\hline $\begin{array}{l}\text { Perusahaan memiliki cara yang efisien } \\
\text { untuk menyebarkan informasi kepada } \\
\text { seluruh tingkat hirarki perusahaan. }\end{array}$ & 0 & 0 & 27 & 25,7 & 20 & 19 & 49 & 46,7 & 9 & 8,6 & 3,38 & Sedang \\
\hline $\begin{array}{l}\text { Perusahaan memiliki cara yang efektif } \\
\text { untuk menyebarkan informasi kepada } \\
\text { seluruh tingkat hirarki perusahaan. }\end{array}$ & 0 & 0 & 15 & 14,3 & 33 & 31,4 & 39 & 37,1 & 18 & 17,1 & 3,57 & Tinggi \\
\hline $\begin{array}{l}\text { Perusahaan menyediakan informasi } \\
\text { kepada saya mengenai customer. }\end{array}$ & 0 & 0 & 25 & 23,8 & 22 & 21 & 51 & 48,6 & 7 & 6,7 & 3,38 & Sedang \\
\hline $\begin{array}{l}\text { Perusahaan menyediakan akses } \\
\text { kepada sumber informasi yang } \\
\text { dibutuhkan saya dalam menyelesaikan } \\
\text { pekerjaan. }\end{array}$ & 1 & 1 & 22 & 21 & 38 & 36,2 & 38 & 36,2 & 6 & 5,7 & 3,25 & Sedang \\
\hline Mean FIS & & & & & & 3952 & & & & & & Sedang \\
\hline
\end{tabular}

Deskripsi Variabel Turnover Intention

Tabel 9. Jawaban Responden Mengenai Turnover Intention

\begin{tabular}{|c|c|c|c|c|c|c|c|c|c|c|c|c|}
\hline \multirow{3}{*}{ Pertanyaan } & \multicolumn{10}{|c|}{ Skor Jawaban } & \multirow{3}{*}{ Mean } & \multirow{3}{*}{ Kategor } \\
\hline & \multicolumn{2}{|c|}{$\begin{array}{c}\text { Sangat } \\
\text { Tidak Setuju } \\
\quad(1) \\
\end{array}$} & \multicolumn{2}{|c|}{$\begin{array}{c}\text { Tidak } \\
\text { Setuju (2) }\end{array}$} & \multicolumn{2}{|c|}{ Netral (3) } & \multicolumn{2}{|c|}{ Setuju (4) } & \multicolumn{2}{|c|}{$\begin{array}{c}\text { Sangat } \\
\text { Setuju (5) }\end{array}$} & & \\
\hline & Jmlh & $\%$ & Jmlh & $\%$ & Jmlh & $\%$ & Jmlh & $\%$ & Jmlh & $\%$ & & \\
\hline $\begin{array}{l}\text { Saya berkeinginan untuk mencari } \\
\text { pekerjaan baru di bidang yang sama di } \\
\text { perusahaan lain. }\end{array}$ & $i^{11}$ & 10,5 & 41 & 39 & 36 & 34,3 & 15 & 14,3 & 2 & 1,9 & 2,58 & Sedang \\
\hline $\begin{array}{l}\text { Saya berkeinginan untuk mencari } \\
\text { pekerjaan baru di bidang yang } \\
\text { berbeda di perusahaaan lain. }\end{array}$ & 4 & 3,8 & 45 & 42,9 & 38 & 36,2 & 17 & 16,2 & 1 & 1 & 2,68 & Sedang \\
\hline $\begin{array}{l}\text { Saya berkeinginan untuk mencari } \\
\text { profesi baru }\end{array}$ & 5 & 4,8 & 47 & 44,8 & 42 & 40 & 10 & 9,5 & 1 & 1 & 2,57 & Rendah \\
\hline $\begin{array}{l}\text { Saya pernah berpikir untuk } \\
\text { meninggalkan perusahaan. }\end{array}$ & 4 & 3,8 & 61 & 58,1 & 29 & 27,6 & 9 & 8,6 & 2 & 1,9 & 2,47 & Rendah \\
\hline $\begin{array}{l}\text { Saya telah mengevaluasi kerugian } \\
\text { yang diakibatkan jika keluar dari } \\
\text { pekerjaan. }\end{array}$ & 3 & 2,9 & 62 & 59 & 31 & 29,5 & 8 & 7,6 & 1 & 1 & 2,45 & Rendah \\
\hline $\begin{array}{l}\text { Saya akan keluar dari pekerjaan dalam } \\
\text { waktu } 6 \text { bulan kedepan. }\end{array}$ & 2 & 1,9 & 56 & 53,3 & 25 & 23,8 & 17 & 16,2 & 5 & 4,8 & 2,69 & Sedang \\
\hline Mean Turnover Intention & & & & & & 2,5713 & & & & & & Rendah \\
\hline
\end{tabular}




\section{Analisis Regresi Berganda}

Dalam model analisis regresi linier berganda, yang dipergunaka sebagai variabel terikat $(\mathrm{Y})$ adalah employee turnover intention, dan sebagai variabel tidak terikat $(\mathrm{X})$ adalah meaningfulness (X1), competence (X2), self-determination (X3), impact (X4), dynamic structural framework (X5), control of workplace decisions (X6) dan fluidity in information sharing (X7). Pada proses pengolahan data, perhitungan menggunakan program SPSS 10.00 . Hasil analisis regresi linier berganda disajikan dalam tabel 10.

Tabel 10. Hasil Perhitungan Koefisien Regresi Linier Berganda

\begin{tabular}{|c|c|c|c|c|}
\hline \multirow[t]{2}{*}{ Model } & \multicolumn{2}{|c|}{ Koefisien } & \multirow{2}{*}{$\begin{array}{c}\mathbf{t} \\
\text { hitung }\end{array}$} & \multirow[t]{2}{*}{ Sig. } \\
\hline & $\mathbf{B}$ & $\begin{array}{c}\text { Std } \\
\text { Error }\end{array}$ & & \\
\hline Konstan & 6,364 & 0,357 & & \\
\hline Meaningfulness & $-0,278$ & 0,071 & $-3,897$ & 0,000 \\
\hline Competence & $-0,002$ & 0,070 & $-0,035$ & 0,972 \\
\hline Self-determination & $-0,129$ & 0,056 & $-2,302$ & 0,023 \\
\hline Impact & $-0,232$ & 0,061 & $-3,808$ & 0,000 \\
\hline Dynamic structural framework & $-0,206$ & 0,065 & $-3,150$ & 0,002 \\
\hline Control of workplace decisions & $-0,156$ & 0,057 & $-2,759$ & 0,007 \\
\hline \multirow[t]{5}{*}{ Fluidity in information sharing } & $-0,089$ & 0,063 & $-1,417$ & 0,160 \\
\hline & $\mathrm{R}^{2}=0,558$ & & & \\
\hline & $\mathrm{R}=0,747$ & & & \\
\hline & $\mathrm{F}=17,46$ & & & \\
\hline & Sig $=0,00$ & & & \\
\hline
\end{tabular}

Hasil pengolahan data pada tabel 10. menunjukkan bahwa:

1. Koefisien determinasi $\left(\mathrm{R}^{2}\right)$ diperoleh angka 0,558 . Hal ini dapat diartikan bahwa besarnya persentase nilai variabel independen (meaningfulness, competence, self-determination, impact, dynamic structural framework, control of workplace decision, dan fluidity in information sharing) untuk menjelaskan variabel dependen (turnover intention) adalah sebesar 55,8 \%, sedangkan sisanya 44,2 \% sisanya dijelaskan oleh variabel lain di luar variabel yang diteliti.

2. Hasil koefisien korelasi (R) diperoleh angka 0,747. Hal ini berarti terdapat hubungan yang kuat antara variabel dependen dan independen.

3. $\mathrm{H}_{1}$ yang menyatakan "variabel-variabel persepsi employee empowerment secara simultan berpengaruh signifikan terhadap employee turnover intention di hotel X" dapat diterima dengan nilai signifikansi sebesar $(0,000)$ lebih kecil dari 0,05 dan nilai $\mathrm{F}$ hitung $(17,464)$ diketahui lebih besar dari $\mathrm{F}$ tabel $(2,10)$. Terdapat pengaruh simultan antara persepsi employee empowerment dengan employee turnover intention menunjukkan bahwa variabel-variabel persepsi employee empowerment secara bersama-sama mampu mencegah terjadinya keinginan karyawan untuk keluar dari perusahaan. Hal ini dapat dibuktikan dengan besarnya nilai rata-rata pendapat yang diberikan oleh karyawan tentang indikator yang membentuk persepsi employee empowerment yang sebagian besar memiliki nilai diatas 3,40 yang artinya empowerment yang dilakukan oleh perusahaan melalui variabel meaningfulness (dengan nilai rata-rata sebesar 4,0984), competence (sebesar 3.9556), self-determination (dengan nilai rata-rata sebesar 3,4190), impact (dengan nilai rata-rata sebesar 3,4063), fluidity in information sharing (dengan nilai rata-rata sebesar 3,3952), dynamic structural framework (dengan nilai rata-rata sebesar 3,2381), control of workplace decisions (dengan nilai rata-rata sebesar 2,8619 ). Nilai ratarata jawaban responden ini juga didukung dengan nilai turnover intention dengan nilai rata-rata sebesar 2,5713 yang menunjukkan bahwa employee empowerment yang dilakukan oleh perusahaan mempengaruhi rendahnya keinginan karyawan untuk keluar dari perusahaan.

4. Lebih lanjut secara parsial, terbukti bahwa lima variabel yaitu: meaningfulness, self-determination, impact, dynamic structural framework, dan control of workplace decisions mempunyai pengaruh yang signifikan terhadap turnover intention dengan nilai signifikansi yang lebih kecil dari 0,05. Namun dua variabel yaitu competence dan fluidity in information sharing ternyata tidak signifikan berpengaruh terhadap turnover intention karena nilai signifikansi yang lebih besar dari 0,05 .

5. $\mathrm{H}_{1}$ yang menyatakan bahwa "variabel meaningfulness merupakan variabel yang paling dominan berpengaruh terhadap employee turnover intention di hotel X" dapat diterima dengan nilai beta yang paling besar yaitu 0,351 dan nilai signifikansi paling kecil yaitu sebesar 0,000 . Terdapat pengaruh dominan faktor meaningfulness terhadap turnover intention karena karyawan merasa bahwa:

a. Pekerjaan yang di lakukan merupakan hal yang sangat penting.

b. Aktivitas kerja yang dilakukan oleh karyawan secara pribadi sangat berarti bagi dirinya.

c. Pekerjaan yang karyawan lakukan sesuai dengan idealismenya.

Maka dengan sendirinya akan ada dorongan dari dalam diri karyawan itu sendiri untuk tetap terus bekerja dan hal ini akan mengurangi keinginan karyawan untuk keluar dari perusahaan. 


\section{KESIMPULAN DAN SARAN}

\section{Kesimpulan}

1. Persepsi employee empowerment berpengaruh terhadap turnover intention.

2. Berdasarkan koefisien kolerasi sebesar $\mathrm{R}=0,747$. Hal ini berarti terdapat hubungan yang kuat antara persepsi employee empowerment dan turnover intention.

3. Employee empowerment yang dilakukan oleh hotel $\mathrm{X}$ secara simultan mampu mengurangi keinginan karyawan untuk keluar dari perusahaan.

4. Berdasarkan nilai signifikansi $t$ hitung dapat diketahui bahwa ada dua variabel persepsi employee empowerment yang tidak signifikan berpengaruh terhadap keinginan karyawan untuk keluar dari perusahaan yaitu: competence dan fluidity in information sharing. Karena nilai signifikansi competence sebesar 0,972 dan fluidity in information sharing sebesar 0,160 lebih besar dari nilai signifikansi yang ditetapkan yaitu 0,05 sedangkan faktor meaningfulnees, selfdetermination, impact, dynamic structural framework, control of workplace decisions secara parsial signifikan berpengaruh terhadap keinginan karyawan untuk keluar dari perusahaan.

5. Berdasarkan pada hasil pengolahan data yang dilakukan, faktor meaningfulness merupakan faktor paling dominan berpengaruh terhadap turnover intention.

\section{Saran}

1. Hotel X sebaiknya lebih memberikan kepercayaan kepada karyawan agar dalam melaksanakan pekerjaan agar tidak bergantung kepada atas.

2. Perusahaan sebaiknya lebih mengoptimalkan setiap briefing dan rapat-rapat yang dilakukan pada setiap bagian untuk mengetahui opini yang diberikan oleh karyawan.

3. Perusahaan memberikan kesempatan yang sama kepada karyawan agar dapat memodifikasi pedoman misalnya dalam pembuatan keputusan yang berhubungan dengan lingkungan kerja yang telah disediakan oleh perusahaan. Perusahaan lebih melibatkan karyawan dalam pembentukan visi dan misi perusahaan.

4. Perusahaan memberikan kesempatan kepada karyawan untuk memberikan masukkan dalam semua aspek karir profesional karyawan.

5. Variabel fluidity in information sharing memiliki nilai rata-rata sedang, karena itu walaupun tidak signifikan terhadap turnover intention, peneliti merasa perlu memberi saran kepada perusahaan agar dapat meningkatkan fluidity in information sharing yaitu dengan cara menyediakan akses kepada sumber informasi yang dibutuhkan karyawan dalam menyelesaikan pekerjaan serta lebih terbuka terhadap karyawan mengenai informasi-informasi yang menyakut functioning perusahaan. Perusahaan sebaiknya menemukan cara yang lebih efisien lagi dalam menyebarkan informasi kepada seluruh tingkat hirarki. Misalnya dengan menciptakan sebuah program komputer yang berfungsi seperti email (intranet) yang hanya digunakan untuk membagi informasi-informasi penting perusahaan. Setiap karyawan, sebelum memulai pekerjaannya di pagi hari,diwajibkan untuk mengetahui informasi terbaru dari perusahaan. Dan untuk karyawan operasional, sebaiknya supervisor dari setiap departemen operasional mengeceknya, kemudian sebelum memulai pekerjaan memberikan briefing kepada karyawan operasional mengenai informasi terbaru dari perusahaan.

6. Pelatihan yang dapat mempertajam pemahaman karyawan tentang employee empowerment perlu diadakan agar dapat lebih meningkatkan dampak dari penyelenggaraan employee empowerment lebih lanjut.

\section{DAFTAR PUSTAKA}

Conger, J. A., \& Kanungo, R. N. (1988). The empowerment process: Integrating theory and practice. Academy of Management Review, 13, 471-482.

Gibson, Ivancevich, Donnely (1985). Organisasi. Jilid 1. $\left(5^{\text {th }}\right.$ ed.). Jakarta: Erlangga.

Harnoto. (2002). Manajemen sumber daya manusia ( $2^{\text {nd }}$ ed.). Jakarta: PT. Prenhallindo.

Handoyo, R. (1987). Hubungan keikatan terhadap perusahaan dengan kepuasaan kerja, absensi dan intensi turnover karyawan pada PT. Busana Rama Textil dan Garment di Tangerang Jawa Barat. Unpublished undergraduate thesis, Fakultas Psikologi Universitas Gajah Mada, Yogyakarta.

Hom, P.W \& Griffeth, R.W. (1991). Structural equation modelling test of a turnover theory: Cross-sectional and longitudinal analysis. Journal of Applied Psychology, 76(3), 350-366.

Kazlauskaite, R., Buciuniene, I., dan Turauskas, L. (2006). Building employee commitment in the hospitality industry. Baltic Journal of Management, 1(3), 300. Retrieved December 23, 2008, from http://proquest.umi.com/pqdweb? $\mathrm{did}=1138782801 \& \mathrm{sid}=2 \& \mathrm{Fmt}=3 \&$ clientId $=20$ 901\&RQT $=309 \&$ VName=PQD 
Lashley, C. (2001). Empowerment: HR strategies for service excellence. Oxford: Butterworth Heinemann.

Ross, Darren L. (1999). HRN in tourism \& hospitality. New York: Cassel.

Light, J.N. (2004). The relationships and effects of employee involvement, employee empowerment, and employee satisfaction by job-type in a large manufacturing environment. Capella University. A dissertaation.

Lum L, Kervin J, and Clark K. (1998). Explaining nursing turnover intent: Job satisfaction, pay satisfaction or organizational commitment. Journal of Organizational Behavior, 24, 543565.

Luthans, F. (1998). Organizational behaviour (5th ed.). Boston: Irwin.

Matthews, R.A., Diaz, W.M. and Cole, S.G. (2003). The organizational empowerment scale. Personnel Review, 32(3), 297-318. Retrieved December 23, 2008, from ABI/INFORM Global (Proquest) database .

Mello, J. A. (2002). Strategic human resources management. Canada: Thomson Learning.

Mishra, A.K \& Spreitzer, G.M. (1998). Explaining how survivors respond to downsizing the role of trust, empowerment, justice, and work redesign. Academy of Management Review, 23(3), 568-588.

Nedd, N. (2006). Perceptions of empowerment and intent to stay. Nursing Economics, Piman: Jan/Feb 2006, 24(1), 13-19. Retrieved December 23, 2008, from http://proquest. umi.com/ pqdweb?did=995470941\&sid=1\&Fmt=4\&clie ntId=20901\&RQT $=309 \&$ VName $=$ PQD

Panggabean, M. S. (2004). Manajemen sumber daya manusia ( $2^{\text {nd }}$ ed.). Bogor Selatan: Ghalia Indonesia.

Parasuraman, S. (1989). Nursing turnover: An integrated model. Research in Nursing and Health., 12, 267-277.

Quinn, R.E. and Spreitzer, G.M. (1997). The road to empowerment: Seven questions every leader should consider. Organizational Dynamics, 26(2), 37-49.

Robbins, S. P. (1994). Essentials of organizational behavior $\left(4^{\text {th }}\right.$ ed.). San Diego State University. USA: Prentice-Hall, Inc.
Roseman, E. (1981). Managing turnover: A positive approach. New York: Amacom.

Salazar, J.P. (2000). The relationship between hospitality employee empowerment, overall job satisfaction, and organizational commitment: a study of race and gender differences. Auburn University. A dissertation.

Sanderson, P. A. (2003). The relationship between empowerment and turnover intentions in a structured environment: An assessment of the Navy's Medical Service Corps. Ph.D. dissertation, Regent University, United States -Virginia. (Publication No. AAT 3144617). Retrieved April 8, 2009. From www.proquest. com

Spreitzer, G. M. (1995). Psychological empowerment in the workplace: Dimensions, measurement, and validation. Academy of Management Journal, 38(5), 1442-1466. From http://proquest.umi.com/pqdweb?did=7748688\&Fmt=4 \&clientId=46969\&RQT $=309 \&$ VName=PQD

Spreitzer, G.M. (1997). Toward a common ground in defining empowerment. Research in Organizational Change and Development, 10, 3162.

Stewart, A. M. (1998). Empowering people: Pemberdayaan sumber daya manusia. Yogyakarta: Kanisius.

Sugiyono. (2008). Metode penelitian kuantitatif, kualitatif, dan $R \& D$. Bandung: Alfabeta.

Sullivan, J. (2009). The ideal turnover rate. Monster.ca. Retrieved February 2, 2009, from http://hiring. monster.ca/hr/hr-best-practices/recruitinghiringadvice/strategicworkforce.../employeeturnoverrate-canada.aspx

Thomas, K.W. and Velthouse, B.A. (1990). Cognitive elements of empowerment: an 'interpretive' model of intrinsic task motivation. Academy of Management Review, 15(4), 666-81. Retrieved January 23, 2009, from ABI/INFORM Global (Proquest) database.

Thoha, M. (1997). Perilaku organisasi: Konsep dasar dan aplikasinya. Jakarta: PT. Raja Grafindo Persada.

Wilkinson, A. (1988). Empowerment: Theory and practice. Personnel Review, 27(1), 40-56. 